\title{
Laparoscopic excision of accessory cavitated uterine mass and its vaginal retrieval in toto
}

\section{Mani Kanmani*, Chinnasamy Kasthuri}

Department of Obstetrics and Gynaecology, Sri Ramakrishna Hospital, Coimbatore, Tamil Nadu, India

Received: 14 January 2021

Accepted: 30 January 2021

\section{*Correspondence:}

Dr. Mani Kanmani,

E-mail: drmkdpi@gmail.com

Copyright: (C) the author(s), publisher and licensee Medip Academy. This is an open-access article distributed under the terms of the Creative Commons Attribution Non-Commercial License, which permits unrestricted non-commercial use, distribution, and reproduction in any medium, provided the original work is properly cited.

\begin{abstract}
Accessory cavitated uterine mass (ACUM), a rare cause of dysmenorrhoea, has to be diagnosed with essential criteria and is to be treated with appropriate surgery. Hereby, presenting the surgical approach by laparoscopy and vaginal retrieval of the specimen in toto as a perfect tool. We report a rare case study of ACUM, a mullerian anomaly in a 27 years old female with severe dysmenorrhoea with secondary infertility, evaluated and diagnosed as ACUM. Preoperative diagnosis and surgical plane evaluation are made by ultrasound and magnetic resonance imaging. Hysteroscopic examination of the cavity was normal and laparoscopic excision of an ill-defined mass in the anterior and right lateral wall of $3 \times 2 \mathrm{~cm}$ followed by retrieval of the specimen through a pouch of Douglas. Myometrial defect sutured. Cut section showed chocolate coloured fluid in the endometrial cavity and the same confirmed by histopathology. This is the first case report doing vaginal retrieval of ACUM in toto.
\end{abstract}

Keywords: Accessory cavitated uterine mass, Laparoscopy ACUM, Mullerian anomaly

\section{INTRODUCTION}

Accessory cavitated uterine mass (ACUM) represents a new Mullerian anomaly that is generally located at the level of insertion of the round ligament. Embryologically, it is possibly related to dysfunction of female gubernaculum resulting in duplication or persistence of paramesonephric tissue. ${ }^{1,2}$ In young females with severe dysmenorrhoea and recurrent pelvic pain, the differential diagnosis are adenomyosis with cystic and degenerated areas, degenerated leiomyoma and malformed uterine horns or isolated juvenile cystic adenomyomas. Here, we report this case to raise awareness about accessory and cavitated uterine mass with functional endometrium and highlight the importance of definite diagnosis and preoperative assessment of surgical planes to guide laparoscopic excision of ACUM the vaginal retrieval of specimen for documentation, thereby avoids laparotomy. Criteria used for diagnosis were 1. An accessory cavitated mass with the habitual orientation of lesion around the round ligament 2. Normal uterus, endometrial cavity, fallopian tubes and ovaries. 3.Cystic components within the lesion showing chocolate coloured content and signal intensity of blood degeneration products 4 . No signs of adenomyosis in the uterus; however, tiny foci of adenomyosis may be seen in the myometrium of ACUM due to increasing in intracystic pressure 5. No pelvic endometriotic deposits 6. Histopathology confirms that cavitated mass lined by functional endometrium with glands and stroma is surrounded by irregularly arranged smooth muscle cells. Foci of adenomyosis were also noticed within myometrium of the mass. Smooth muscle cells stain positive for desmin estrogen receptors (ER) and progesterone receptors (PR). ${ }^{1,2}$

\section{CASE REPORT}

A 27 years old adult female, married for 6 years, with history of abortion, anxious to conceive, admitted with the history of severe dysmenorrhoea on and off for 4 years, not relieved with NSAIDs and OCP s, admitted for evaluation and management. Clinical examination, 
revealed enlarged uterus, no forniceal tenderness. USG pelvis showed well defined isoechoic lesion of $30 \times 23 \times 26$ $\mathrm{mm}$ with the central hyperechoic area in the right lateral wall of uterus suggestive of accessory cavitated uterine mass. The distance between the serosal layer and ACUM was $10 \mathrm{~mm}$ and the distance between endometrium and accessory uterine mass was $11 \mathrm{~mm}$. This calculation helps us to identify the depth of ACUM and its relationship with endometrium. MRI pelvis confirmed $30 \times 25 \times 27 \mathrm{~mm}(\mathrm{TR} \times \mathrm{CC} \times \mathrm{AP})$ slightly T2 Hypointense, $\mathrm{T} 1$ isointense well defined rounded lesion with central T1hyperintense area blooms on gradient sequences noted in the right lateral wall of uterus favouring the possibility of accessory cavitated uterine mass. Hence, proceeded for Laparoscopic excision of ACUM. In order to avoid spillage and to remove the specimen in toto for documentation, retrieval of the specimen through POD was planned.

\section{Procedure}

Under GA, hysteroscopy confirmed normal uterine cavity, normally appearing bilateral ostia and adequate endometrial cavity in panoramic view. Through laparoscopy, the uterus and other pelvic structures were inspected. The uterus appeared broad, asymmetrical with a bulge in the right lateral wall, close to the round ligament. Both tubes and ovaries were normal. Diluted vasopressin was injected near the mass and a linear incision was made over the anterior surface of the mass with Harmonic scalpel. The mass was dissected out and removed en masse without any damage to the myometrium. The normal endometrial cavity was not entered. The myometrial defect was closed with V-Loc. Specimen retrieved through pouch of Douglas (POD). The vaginal wall closed with 2-0 chromic catgut. On incising the specimen, chocolate coloured fluid of about $10 \mathrm{ml}$ flew out due to increased intracystic pressure. Endometrial lining with well-formed cavity and surrounding myometrium with foci of adenomyosis was seen and the specimen was sent for HPE. Postoperative period was uneventful and the patient improved symptomatically. On histopathologic examinationfunctioning endometrial lining with surrounding myometrium noted.

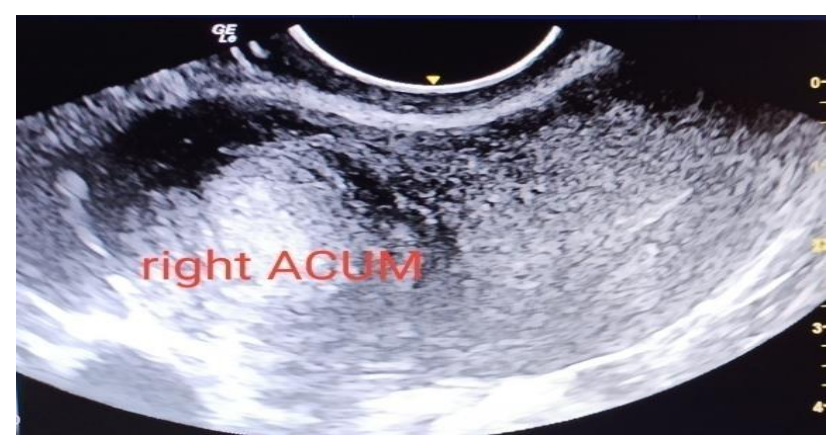

Figure 1: Ultrasound image of central mixed echogenicity in a mass.

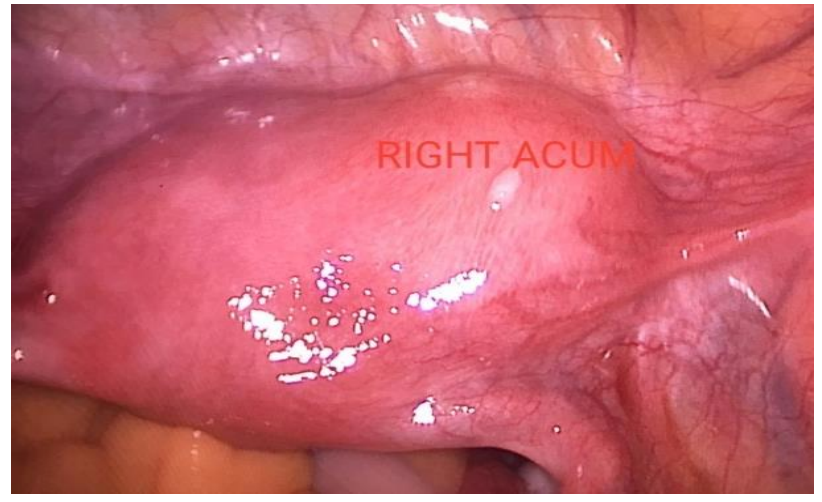

Figure 2: Laparoscopic view of right side ACUM.

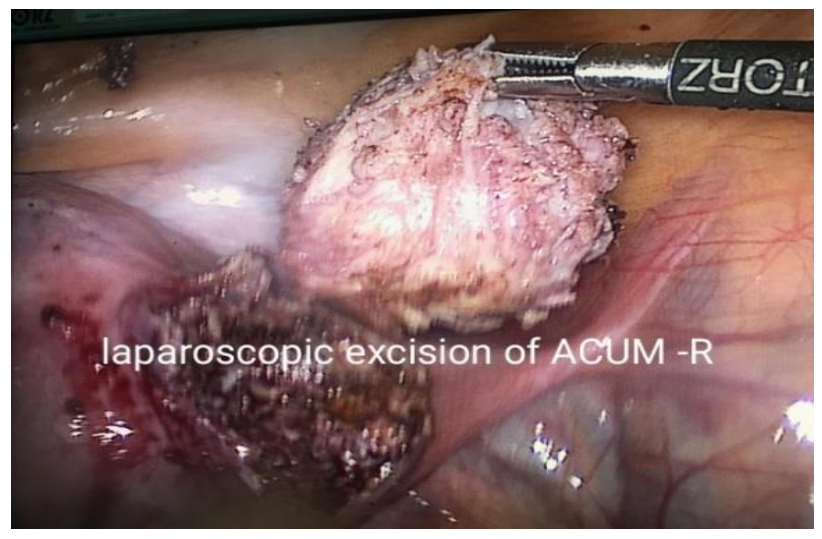

Figure 3: Complete excision of mass.

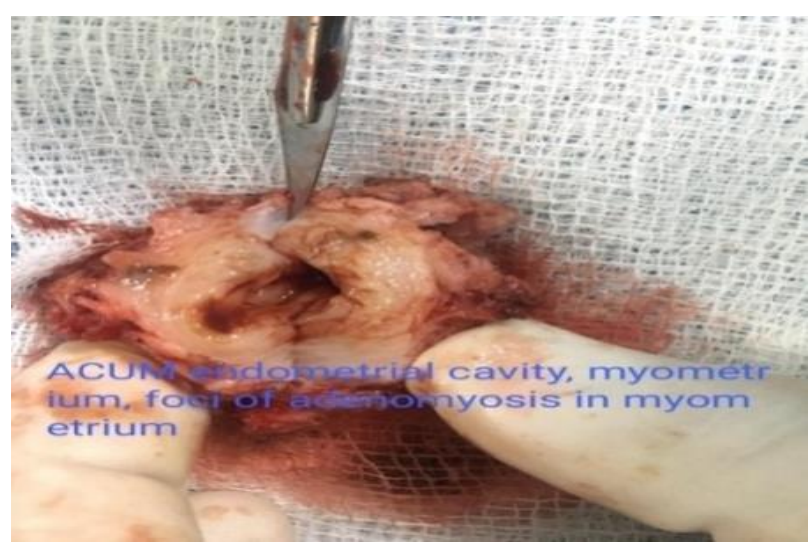

Figure 4: Cut section of mass of endometrial cavity and surrounding myometrium with adenomyotic spots.

\section{DISCUSSION}

For preoperative planning, an ultrasound pelvis and confirmation of diagnosis by the MRI pelvis are effective. ${ }^{3}$ The distance between ACUM and the normal endometrial cavity can be assessed preoperatively to guide us during laparoscopy in assessing the depth of dissection. In our case, the distance between ACUM and the endometrium was $11 \mathrm{~mm}$. Our patient presented with infertility and severe dysmenorrhoea, who has been 
treated with OCP'S for 5 years cyclically to relieve her symptoms, but she had only little relief. Definite diagnosis was made with imaging and proceeded for surgery. Regarding surgical excision, various modalities of excision of ACUM were described in the literature, by laparoscopy, laparotomy and robotic-assisted laparoscopy. ${ }^{4}$ Acien et al, reported laparotomy in his cases for the better of documentation of ACUM. ${ }^{5}$ In our case, though it was an ill-defined mass, with careful dissection, the plane was identified from the normal myometrium and it was dissected out en masse. For the documentation we removed the mass without spillage of chocolate coloured fluid and so the specimen was removed through POD, then the posterior vaginal wall is sutured. We prefer the laparoscopy for ACUM excision, not only as the minimally invasive procedure but the mass can be removed as a whole when it is combined with the vaginal route for retrieval, particularly in sexually active patients. In 2013, Bedaiwy et al, reported laparoscopic excision of ACUM and was removed with $10 \mathrm{~mm}$ port done through a telescope. In an adolescent girl where manipulation through the vagina is generally not practised or accepted, unless it is very much necessary, excision of the specimen through lateral ports can be done. ${ }^{6}$ In 2015, Paul et al, reported 3 cases of ACUM presented at varying age. He did laparoscopic excision for all 3 cases, where the ACUM was ruptured and chocolate material let out then the mass was removed using traction with myoma screw. ${ }^{7}$ In our case, we did not use myoma screw to avoid opening up of cavity; instead, we used toothed graspers for traction and mass excision using harmonics.

\section{CONCLUSION}

ACUM is a rare Mullerian anomaly in women with severe dysmenorrhoea requires definitive and timely diagnosis and management. Even though its true incidence is not available, we should be aware of this condition and intervene at the right time. Here we presented a rare case report of ACUM and its laparoscopic excision combined with the vaginal route for retrieval to avoid spillage and for the documentation purpose.
Funding: No funding sources Conflict of interest: None declared Ethical approval: Not required

\section{REFERENCES}

1. Acién P, Acién M, Fernández F, Mayol MJ, Aranda I. The cavitated accessory uterine mass: a Müllerian anomaly in women with an otherwise normal uterus. Obstetr Gynecol. 2010;116(5):1101-9.

2. Acién M, Acién P. Normal embryological development of the female genital tract. InFemale Genital Tract Congenital Malformations, Springer, London. 2015;3-14.

3. Peyron N, Jacquemier E, Charlot M, Devouassoux M, Raudrant D, Golfier F et al. Accessory cavitated uterine mass: MRI features and surgical correlations of a rare but under-recognised entity. Euro Radiol. 2019;29(3):1144-52.

4. Akar ME, Leezer KH, Yalcinkaya TM. Robotassisted laparoscopic management of a case with juvenile cystic adenomyoma. Fertility Sterility. 2010;94(3):e55-6.

5. Acién P, Bataller A, Fernández F, Acién MI, Rodríguez JM, Mayol MJ. New cases of accessory and cavitated uterine masses (ACUM): a significant cause of severe dysmenorrhea and recurrent pelvic pain in young women. Human Reprod. 2012;27(3):683-94.

6. Bedaiwy MA, Henry DN, Elguero S, Pickett S, Greenfield M. Accessory and cavitated uterine mass with functional endometrium in an adolescent: diagnosis and laparoscopic excision technique. J Pediatr Adolescent Gynecol. 2013;26(4):e89-91.

7. Paul PG, Chopade G, Das T, Dhivya N, Patil S, Thomas M. Accessory cavitated uterine mass: a rare cause of severe dysmenorrhea in young women. J Minimally Invasive Gynecol. 2015;22(7):1300-3.

Cite this article as: Kanmani M, Kasthuri C. Laparoscopic excision of accessory cavitated uterine mass and its vaginal retrieval in toto. Int $\mathrm{J}$ Reprod Contracept Obstet Gynecol 2021;10:1177-9. 